\title{
Resenha \\ Portraits of Pioneers in Developmental Psychology
}

Pickren, W. E., Dewsbury, D. A., \& Wertheimer, M. (Eds.). (2011).

Portraits of pioneers in Developmental Psychology.

New York: Psychology Press.

\author{
Idonézia Collodel Benetti* \\ Centro Universitário Barriga Verde, Orleans, Brasil \\ Universidade Federal de Santa Catarina, Florianópolis, Brasil
}

\begin{abstract}
Resumo
O presente trabalho é a recensão da obra Portraits of Pioneers in Developmental Psychology, lançada em 2011 e ainda não traduzida para o português brasileiro. Como sinalizado no título, é uma coletânea que alberga alguns pioneiros da psicologia do desenvolvimento. Em sua extensão, relatos da vida pessoal e acadêmica de 16 estudiosos desta área são oferecidos ao leitor, bem como as experiências e contribuições destes pioneiros para esta especialidade da psicologia.

Palavras-chave: Psicologia, desenvolvimento, pioneiros.
\end{abstract}

\begin{abstract}
The present paper is a recension of the book Portraits of Pioneers in Developmental Psychology released in 2011 which has not been translated into Brazilian Portuguese yet. It is a collection of works in honor to some pioneers in the developmental psychology field. In its extension, the reader can find some personal and academic reports about 16 scholars in this area of knowledge, as well as their experiences and contributions to this field of psychology.

Keywords: Psychology, development, pioneers.
\end{abstract}

Esta obra pertence à série Pioneers in Psychology, publicada sob a responsabilidade da Divisão 1 (Psicologia Geral) e da Divisão 26 (História da Psicologia) da Sociedade Geral de Psicologia da APA - American Psychological Association - com o primeiro volume trazido a público em 1991. Os volumes II a VI ficaram conhecidos em 1996, 1998, 2000, 2003 e 2006, respectivamente. O volume VII, razão desta recensão, foi publicado em 2011, e toda a série tem como fio condutor a preocupação em apresentar os estudiosos mais proeminentes e/ou aqueles que mais contribuíram para a área da psicologia do desenvolvimento.

Uma curiosidade marca estas publicações desde a ideia que norteou a concepção da série, na década de 70: nem todos os nomes apresentados são familiares àqueles que trilham os caminhos da psicologia do desenvolvimento. Alguns deles não são psicólogos, no senso tradicional dos estudos em psicologia, porém sua relevância e contribuição, esquecidas durante gerações, são dignas de nota. Por esta razão, cada capítulo publicado é uma tentativa de

*Endereço para correspondência: Centro Universitário Barriga Verde, Rua Pe. João Leonir Dall'Alba, s/n, Bairro Murialdo, Orleans, SC, Brasil 88870-000. Tel.: 0483466 0192,048 99084646. E-mail: idonezia@hotmail.com fazer ressurgir tais contribuições, alinhavando o apoio por eles oferecido, de modo a providenciar um senso de continuidade na história da psicologia.

O volume VII, particularmente, presenteia o leitor com vislumbres da vida pessoal e acadêmica de 16 grandes nomes da história da psicologia trazidos por estudiosos proeminentes que foram convidados a preparar os $17 \mathrm{ca}-$ pítulos contidos nesta obra, versando sobre esses pioneiros e suas experiências na área. Alguns dos estudiosos mencionados foram professores dos autores convidados. Alguns destes autores são professores universitários e, na condição de ex-alunos, fazem conexões entre o legado destes desbravadores e a condição atual da psicologia; em outras palavras, servem de "ponte" entre os pioneiros e os acadêmicos de psicologia.

Cada volume apresenta uma especialidade da psicologia e, escrito em um estilo pessoal, informal e, às vezes, com pitadas de humor, o conteúdo desta obra concentrase em um campo específico: a psicologia do desenvolvimento. Neste sentido, 16 figuras-chave nesta área representam este conteúdo de várias maneiras trazendo mais pioneiros de outros países fora dos Estados Unidos da América, enfatizando o trabalho das pioneiras do gênero feminino e das pioneiras que fazem parte das minorias étnicas. 
Os capítulos centrais destacam as muitas contribuições de pioneiros europeus para a psicologia do desenvolvimento - Jean Piaget, Charlotte Bühler, Heinz Werner, e Lev Vygotsky - cujos estudos tiveram influência significativa para a compreensão do desenvolvimento humano. Estes autores tiveram seus trabalhos aplicados nos Estados Unidos por Joseph McVicker Hunt e no Brasil por Helena Antipoff, ambos interpretando, nos seus respectivos contextos, os aportes oferecidos por estes pioneiros. A autoria do capítulo sobre Helena Antipoff é da brasileira Regina Helena F. Campos, professora de Psicologia Educacional na Universidade Federal de Minas Gerais (UFMG).

O volume VII, ainda não traduzido para o português brasileiro, é o primeiro da série a trazer um ensaio introdutório preparado por um dos editores Wade E. Pickren professor de psicologia em Pace University (New York) - preparando o leitor para entender mais substancialmente as ideias de cada um dos pioneiros incluídos nesta obra. Os outros dois editores são Donald A. Dewsbury - Professor emérito de psicologia na Universidade da Flórida, e Michael Wertheimer - Professor emérito da Universidade do Colorado. Sem sombra de dúvida, os editores foram extremamente cuidadosos ao escolher teóricos notáveis, cujos trabalhos tiveram grande impacto nesta disciplina.

Este volume, diferentemente dos anteriores, traz como novidade um ensaio no final do livro, também escrito por Wade E. Pickren. Nestes registros ele traça conexões entre as contribuições oferecidas pelos pioneiros eleitos, discutindo a importância destes cientistas para que novas áreas de pesquisa fossem descortinadas. Além disso, ele aponta a relevância dos escritos de cada um deles para o avanço dos estudos neste campo do conhecimento.

Resumindo, o conteúdo desta obra, distribuído em 351 páginas, está ancorado nas ideias dos seguintes cientistas: (1) Arnold Gesell - considerado um maturacionista, estabelece parâmetros para os estudos experimentais na infância; (2) Florence L. Goodenough - com características de inovação e pioneirismo no desenvolvimento humano, foi figura-chave para o acesso aos métodos de desenvolvimento para a compreensão da criança; (3) Heinz Werner - trabalha um modelo de teoria da diferenciação no desenvolvimento, e integração das diferentes esferas envolvidas na experiência dos indivíduos. Este modelo proporciona maneiras de conceitualizar as diferenças individuais e culturais, bem como as mudanças na vida do indivíduo; (4) Helena Antipoff em uma perspectiva da psicologia de Genebra, com base na corrente sócio-histórica da psicologia soviética, seus trabalhos caracterizam-se pela visão de democracia e direitos humanos; (5) Charlotte Bühler - enfatiza a psicologia clínica e humanística, e contribui para o movimento humanístico na psicologia, liderando o pioneirismo nas pesquisas em psicologia do desenvolvimento;
(6) Jean Piaget - teórico da mente infantil, interessado nos processos do desenvolvimento qualitativo do conhecimento; (7) Lev Vygotsky - filólogo e defectologista, influenciou grandemente a psicologia desenvolvimental e cognitiva, e ajudou a criar o campo da psicologia sociocultural; (8) Lois Barclay Murphy - pioneiro do positivismo, com trabalhos relacionados à personalidade e ao desenvolvimento infantil, influenciou os modernos trabalhos nesta área.

Em continuidade, mais autores ainda figuram nesta obra, a saber: (9) Roger Barker - um tipo diferente de desenvolvimentalista, pioneiro na psicologia social e desenvolvimental, mudou a maneira como a psicologia pensava o comportamento social; (10) Robert W. White - uma vida no estudo de vidas; sua abordagem, relacionada a problemas clínicos, estimulou muitas inovações na área da psicologia clínica e da personalidade; (11) Joseph McVicker Hunt - considerado o psicólogo da idade de ouro, suas pesquisas conduziram a importantes conclusões e decisões políticas, que providenciaram o enriquecimento de contextos para o desenvolvimento da primeira infância; (12) Sidney W. Bijou - considerado como uma excepcionalidade no seu campo de atuação - desenvolveu uma abordagem para tratar transtornos da infância usando terapia comportamental; (13) John Paul Scott - foi um dos principais pioneiros no estudo da genética, desenvolvimento e comportamento social, e no estudo do comportamento genético; (14) Eleanor J. Gibson - aprender a perceber, perceber para aprender. Seu trabalho em percepção visual serviu de base para investigações na percepção visual das crianças e seu papel nas questões voltadas à adaptação; (15) Mamie Phipps Clark - exerceu impacto profundo nas oportunidades educacionais para as crianças americanas, e seus estudos tiveram componentes cruciais frente à suprema corte americana, que declarou a segregação racial inconstitucional nas escolas públicas; (16) Lawrence Kohlberg - estudioso da biografia moral, psicologia moral e pedagogia moral, tenta conciliar filosofia e psicologia, e lança bases para os debates atuais em desenvolvimento moral.

Como se pode observar, este livro deve sua existência ao esforço de muitos autores e de seus editores. Com o conteúdo nele apresentado, este volume está endereçado como texto suplementar para estudantes e professores de cursos de graduação, pós-graduação, ou cursos que ofereçam estudos em história da psicologia, desenvolvimento infantil, psicologia do desenvolvimento, nos cursos de psicologia, educação e desenvolvimento humano, em geral.

Além disso, tendo em vista a abrangência dos escritos apresentados nesta obra, ousa-se recomendar seu conteúdo para todos aqueles que se interessam pela psicologia do desenvolvimento. Não apenas para psicólogos, mas também para sociólogos e historiadores da área das ciências humanas, filósofos e profissionais que trabalham em educação, neuropsicologia, e leitores que se interessam 
Benetti, I. C. (2012). Resenha: Portraits of Pioneers in Developmental Psychology.

pela história das ideias e do curso da vida de grandes cientistas.

Concluindo, vale acrescentar que este volume faz o leitor lembrar o quanto se pode aprender dos antecessores que se dedicaram a estudar a psicologia do desenvolvimento. Vale enfatizar, também, que os leitores desta obra terão uma leitura que vai além da informação e das contribuições na área, uma vez que traz aspectos de provocação, surpresa, deleite, e satisfação, com um toque pessoal dos autores, porém sem perder a precisão científica. Como resultado, é bastante provável que se tenha leitores irresistivelmente interessados e engajados no consumo de cada página. É uma obra que, sem dúvida, engrandece o acervo de todo o psicólogo. 
